\title{
Emotion regulation before and after transcranial magnetic stimulation in obsessive compulsive disorder
}

\author{
S. J. de Wit ${ }^{1,2 *}$, Y. D. van der Werf ${ }^{2,3}$, D. Mataix-Cols ${ }^{4}$, J. P. Trujillo ${ }^{1,3}$, P. van Oppen ${ }^{1}$, \\ D. J. Veltman ${ }^{1,2}$ and O. A. van den Heuvel ${ }^{1,2,3}$ \\ ${ }^{1}$ Department of Psychiatry, VU University Medical Center, Amsterdam, The Netherlands \\ ${ }^{2}$ Neuroscience Campus Amsterdam, The Netherlands \\ ${ }^{3}$ Department of Anatomy and Neurosciences, VU University Medical Center, Amsterdam, The Netherlands \\ ${ }^{4}$ Department of Clinical Neuroscience, Centre for Psychiatric Research and Education, Karolinska Institutet, Stockholm, Sweden
}

Background. Impaired emotion regulation may underlie exaggerated emotional reactivity in patients with obsessive compulsive disorder $(\mathrm{OCD})$, yet instructed emotion regulation has never been studied in the disorder.

Method. This study aimed to assess the neural correlates of emotion processing and regulation in 43 medication-free OCD patients and 38 matched healthy controls, and additionally test if these can be modulated by stimulatory (patients) and inhibitory (controls) repetitive transcranial magnetic stimulation (rTMS) over the left dorsolateral prefrontal cortex (dlPFC). Participants performed an emotion regulation task during functional magnetic resonance imaging before and after a single session of randomly assigned real or sham rTMS. Effect of group and rTMS were assessed on self-reported distress ratings and brain activity in frontal-limbic regions of interest.

Results. Patients had higher distress ratings than controls during emotion provocation, but similar rates of distress reduction after voluntary emotion regulation. OCD patients compared with controls showed altered amygdala responsiveness during symptom provocation and diminished left dIPFC activity and frontal-amygdala connectivity during emotion regulation. Real $v$. sham dIPFC stimulation differentially modulated frontal-amygdala connectivity during emotion regulation in OCD patients.

Conclusions. We propose that the increased emotional reactivity in OCD may be due to a deficit in emotion regulation caused by a failure of cognitive control exerted by the dorsal frontal cortex. Modulatory rTMS over the left dlPFC may influence automatic emotion regulation capabilities by influencing frontal-limbic connectivity.

Received 19 July 2014; Revised 30 April 2015; Accepted 5 May 2015; First published online 1 June 2015

Key words: Dorsolateral prefrontal cortex, emotion regulation, functional magnetic resonance imaging, obsessive compulsive disorder, transcranial magnetic stimulation.

\section{Introduction}

Obsessive compulsive disorder (OCD) is a debilitating psychiatric disorder characterized by the presence of obsessions (repetitive intrusive thoughts) and/or compulsions (repetitive ritualistic behaviors; APA, 2013). When confronted with disease-relevant stimuli patients with OCD, compared with healthy individuals, experience higher anxiety levels (van den Heuvel et al. 2004; Schienle et al. 2005), greater attentional bias (van den Heuvel et al. 2005b; Moritz et al. 2009) and increased

* Address for correspondence: S. J. de Wit, MD, Department of Psychiatry, VU University Medical Center, Medical Faculty, Room MF-G102, van der Boechorststraat 7, 1081 BT, Amsterdam, The Netherlands.

(Email: st.dewit@vumc.nl) brain activity as measured by positron emission tomography and functional magnetic resonance imaging (fMRI) in ventral frontal and (para)limbic regions such as the rostral anterior cingulate cortex (rACC) and the amygdala (Rotge et al. 2008). Cognitive-behavior therapy (CBT) is the first-line treatment of choice for OCD (Franklin \& Foa, 2011). In addition to exposure in vivo with response prevention, CBT for OCD also involves teaching patients emotion regulation strategies to help cognitively reframe, i.e. reappraise, negative symptom-eliciting situations as non-threatening. It has been hypothesized that the exaggerated emotional reactivity in OCD is related to emotion regulation impairments (Mataix-Cols \& van den Heuvel, 2006).

Emotion regulation is thought to result from an intricate interplay between automatic bottom-up appraisals of a given stimulus in ventral emotion processing 
(a)

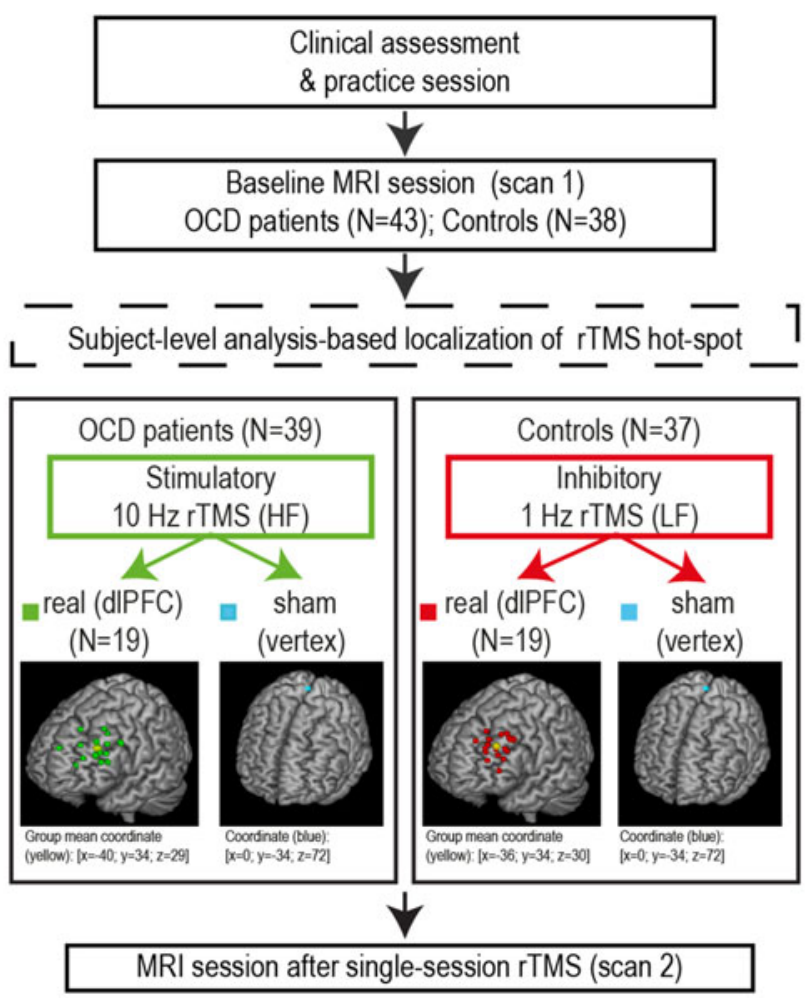

(b)

Task design with two instruction conditions:

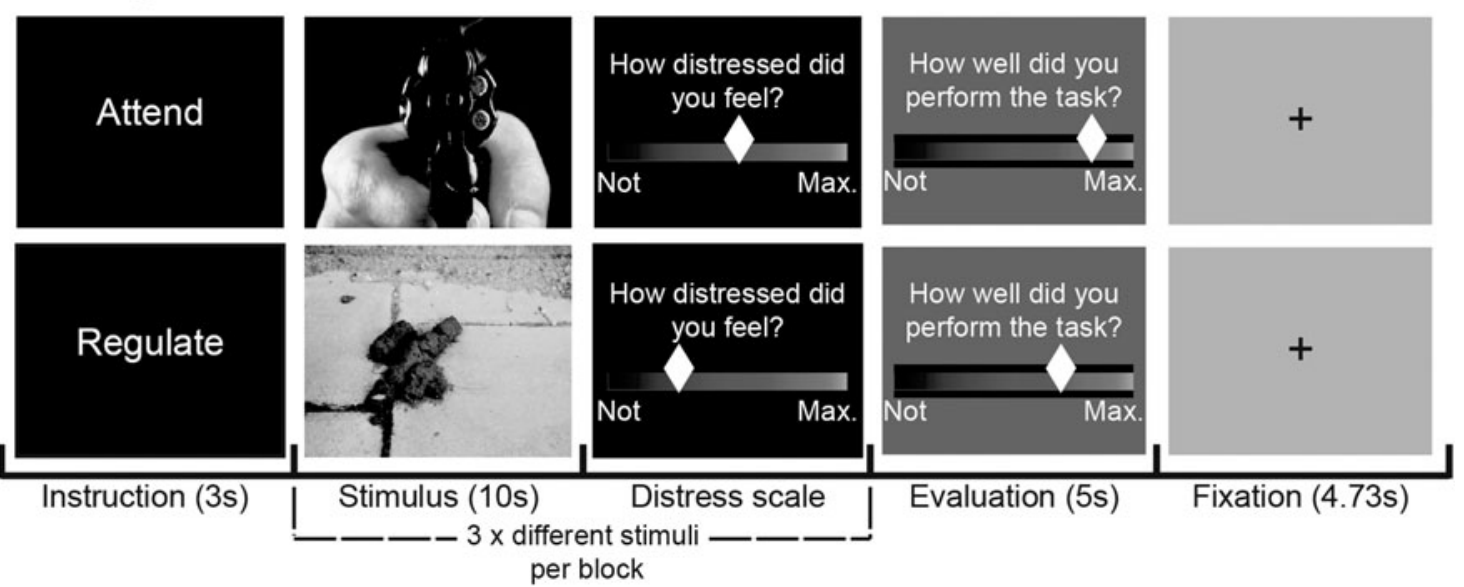

Fig. 1. (a) Design - study. Participants visited the VU University medical center on three occasions within the course of 1-4 weeks. During the first session participants underwent a psychiatric screening and practiced the emotion regulation task. During the second session participants had a first (baseline) functional magnetic resonance imaging (fMRI) scan session. During the third session participants received real or sham repetitive transcranial magnetic stimulation (rTMS) prior to a second fMRI scan session. The location of rTMS stimulation spots, i.e. individual dlPFC hot-spots and group mean coordinate (yellow) of OCD patients (left; green), controls (right; red), and the vertex coordinate (blue), are displayed at the bottom. Stimulation spots and all reported imaging results are overlain on the ch2better MNI template with MRIcron (http://www. mccauslandcenter.sc.edu/mricro/ mricron), and all reported coordinates (x/y/z) are in Montreal Neurological Institute (MNI) space. HF, High-frequency $(10 \mathrm{~Hz})$; LF, low frequency $(1 \mathrm{~Hz})$. (b) Design - emotion regulation task. Participants viewed general fearful stimuli, neutral stimuli, and three OCD-related picture categories targeting contamination concerns (OCD wash), checking (OCD check) and ordering (OCD symmetry) under two possible instruction conditions. Participants attended to or regulated fear or OCD-related stimuli; attending to neutral stimuli was the baseline condition. Depicted are two blocks with the two possible task instructions. During the regulate condition participants were instructed to 'reappraise [i.e. reinterpret] the stimulus such that it elicits less negative affect'. During the attend condition participants were instructed to 'experience the stimulus naturally'. Fear and OCD-related pictures were presented both during attend and regulate; neutral only during 
regions such as the amygdala, and top-down stimulus appraisal by mostly dorsal frontal control regions such as dorsolateral prefrontal cortex (dlPFC) and the dorsomedial prefrontal cortex (dmPFC; medial frontal wall including the (pre)supplementary motor area (SMA) and dorsal ACC) (Phillips et al. 2003a; Ochsner $\&$ Gross, 2007). These frontal and cingulate areas are part of fronto-parietal cognitive-linguistic control networks implicated in effortful (i.e. explicitly applied) reappraisal by cognitively reframing the affective meaning of a negative stimulus in more neutral terms (Dosenbach et al. 2007; Ochsner \& Gross, 2007). Dysfunctional interactions of the dorsal-ventral circuitries are hypothesized to be responsible for pathological emotional experiences in psychiatric patients (Phillips et al. 2003b). Studies in non-psychiatric participants indeed showed that cognitive reappraisal recruits the dIPFC and dmPFC, resulting in down-regulation of the amygdala (Ochsner et al. 2012). Impaired emotion regulation is found in anxiety (Goldin et al. 2009a; Hermann et al. 2009) and depression (Johnstone et al. 2007; Kanske et al. 2012). In OCD, structural and functional neuroimaging studies have shown deficits in brain areas associated with the ventral-dorsal circuitries (Menzies et al. 2008; de Wit et al. 2012, 2014). Some of these functional deficits have shown to normalize after symptom improvement (e.g. Huyser et al. 2010; Vriend et al. 2013). These findings suggest the hypothesis that failure in emotion regulation in OCD may be related to either a deficit in dorsal control functioning and/or hyperactivation in the ventral system. The neural correlates of instructed effortful emotion regulation in OCD, however, have never been studied.

With repetitive transcranial magnetic stimulation (rTMS) activity of the dorsal system (and therefore also cognitive control) may be modulated. rTMS is a non-invasive brain stimulation technique in which a patch of neural tissue is electrically stimulated by rapidly changing electromagnetic fields. A single session of rTMS changes neural functioning from minutes to hours after stimulation. Single-session high-frequency (HF) rTMS $(>5 \mathrm{~Hz})$ is thought to result in temporary excitation of a brain area, and low-frequency (LF) rTMS $(\leq 1 \mathrm{~Hz})$ in inhibition (Reithler et al. 2011). Single-session rTMS on frontal-parietal regions in combination with $\mathrm{fMRI}$ is used to probe brain function and has been shown to modulate behavior and brain activity during resting state, executive functioning and emotional tasks in healthy and clinical samples
(Harmer et al. 2001; Guse et al. 2010; van der Werf et al. 2010; van den Heuvel et al. 2013). A multi-modal imaging study combining rTMS with fMRI enables visualization of its effects on instructed emotion regulation and may herald future clinical studies combining rTMS with CBT in OCD.

The present study aimed to increase our understanding of the neural basis of OCD by probing emotional reactivity and regulation in medication-free adults with OCD and demographically matched healthy controls. Additionally, we wanted to visualize the effect of rTMS on emotion regulation. To this aim, we employed an emotion regulation paradigm with general fear and OCD-specific stimuli during fMRI scanning before and after a single session of rTMS on the left dIPFC using individual fMRI-based neuronavigation. We hypothesized that in OCD patients compared with controls, effortful emotion regulation would result in less effective anxiety reduction, associated with decreased recruitment of dorsal cognitive control areas. Further, we hypothesized that stimulatory HF rTMS $v$. sham would improve emotion regulation in patients, whereas inhibitory LF rTMS $v$. sham would temporarily impair it in controls.

\section{Method \\ Study procedure}

Overall, 43 OCD patients and 38 controls participated in the study (see Fig. $1 a$ for study design, Table 1 for sample characteristics, and Supplementary Method S1.1 in the online data supplement for exclusions). Patients were recruited through outpatient clinics within The Netherlands OCD Association (Schuurmans et al. 2012), the Academic Anxiety Center Altrecht (Utrecht, the Netherlands) and online advertisements. Controls were recruited by local and online community advertisements.

We screened all participants for Axis-I psychiatric disorders with the Structural Clinical Interview for DSM-IV (First et al. 2002). OCD severity and symptom dimensions were assessed with the Yale-Brown Obsessive-Compulsive Scale (YBOCS; Goodman et al. 1989) and the Padua Inventory - Revised (Padua-IR; Van Oppen et al. 1995), respectively. Mood was assessed with the Montgomery-Åsberg Depression Rating Scale (MADRS; Montgomery \& Åsberg, 1979). The emotion regulation questionnaire (ERQ; Gross \&

attend. For each block three pictures of a similar picture type were presented. After each picture participants rated their level of distress. After three pictures, participants were asked to evaluate how well they felt able to perform the task. Each block ended with a washout period (fixation). Each session 27 blocks (three blocks per condition) were presented with a total task duration of about $26 \mathrm{~min}$. 
Table 1. Demographic and clinical characteristics

\begin{tabular}{|c|c|c|c|c|c|c|}
\hline & \multicolumn{2}{|c|}{ OCD patients $(N=43)$} & \multicolumn{2}{|c|}{ Controls $(N=38)$} & \multicolumn{2}{|c|}{ Statistical analysis } \\
\hline & Mean & S.D. & Mean & S.D. & $t(\mathrm{df}=79)$ & $p$ value \\
\hline \multicolumn{7}{|l|}{ Demographic data } \\
\hline Age (years) & 38.4 & 10.0 & 39.6 & 11.4 & -0.517 & 0.606 \\
\hline Gender [men:women (\% men)] & $21: 22$ & $(49 \%)$ & $18: 20$ & $(47 \%)$ & $\chi^{2}=0.017$ & 0.895 \\
\hline Handedness [right:left (\% right)] & $36: 7$ & $(84 \%)$ & $34: 4$ & $(90 \%)$ & $\chi^{2}=0.569$ & 0.451 \\
\hline Educational level (years) ${ }^{\mathrm{a}}$ & 5.9 & 1.9 & 5.9 & 2.0 & $796.5^{\mathrm{b}}$ & 0.845 \\
\hline \multicolumn{7}{|l|}{ Clinical data } \\
\hline YBOCS score (points) & 21.6 & 6.1 & - & - & - & - \\
\hline Padua-IR, total score (points) & 53.4 & 25.0 & 9.0 & 8.3 & $54.5^{\mathrm{b}}$ & $<0.001$ \\
\hline Padua-IR, washing score (points) & 10.1 & 10.1 & 1.3 & 2.5 & $322.0^{\mathrm{b}}$ & $<0.001$ \\
\hline Padua-IR, checking score (points) & 13.2 & 6.9 & 1.9 & 2.6 & $126.0^{\mathrm{b}}$ & $<0.001$ \\
\hline Padua-IR precision score (points) & 5.8 & 4.6 & 0.8 & 1.1 & $245.5^{\mathrm{b}}$ & $<0.001$ \\
\hline MADRS score (points) & 11.2 & 8.1 & 0.8 & 1.4 & $102.0^{\mathrm{b}}$ & $<0.001$ \\
\hline ERQ Reappraisal & 4.1 & 1.3 & 4.9 & 1.1 & $508.0^{\mathrm{b}}$ & 0.003 \\
\hline ERQ Suppression & 3.2 & 1.4 & 3.0 & 1.1 & $758.0^{\mathrm{b}}$ & 0.579 \\
\hline Current co-morbidity [Y:N (\% yes)] & $24: 19$ & $56 \%$ & - & - & - & - \\
\hline
\end{tabular}

John, 2003; Koole \& Jostmann, 2004) assessed to what extent participants used reappraisal and suppression as emotion modulating strategies in daily life. Handedness was assessed with the Edinburgh Handedness Inventory (Oldfield, 1971). All participants were aged between 18 and 65 years and all participants had (corrected to) normal vision.

Exclusion criteria were psychoactive medication use, current or past psychosis, major physical illness, a history of major neurological illness and MRI contraindications. Patients were medication-free for at least 4 weeks. Patients had to have a primary diagnosis of OCD, but without predominant hoarding; psychiatric co-morbidity (including tic disorders) was not an exclusion criterion. Controls had no current DSM-IV Axis-I diagnosis.

The authors assert that all procedures contributing to this work comply with the ethical standards of the local medical ethical review board on human experimentation and with the Helsinki Declaration of 1975, as revised in 2008. All participants provided written informed consent.

\section{Sample characteristics}

OCD patients and controls at baseline were well matched (Table 1). Patients compared with controls scored higher on OCD and depression measures and had lower ERQ-reappraisal but similar ERQ- suppression scores. Twenty-four (56\%) OCD patients met criteria for one or more current co-morbid Axis-I diagnosis (see Supplementary Method S1.1).

Randomization of patients and controls to the real and sham rTMS condition resulted in equal demographic, clinical and baseline task-performance measures (all $p>0.1$; data not shown), apart from co-morbidity, which was significantly higher in patients in the real $(79 \%) v$. the sham $(30 \%)$ rTMS group $(p=0.004)$. The mean interval between MRI sessions (11 days), between rTMS and MRI scanning (6 $\mathrm{m} 10 \mathrm{~s})$, and the resting motor threshold (48\%), did not differ significantly between the real and sham rTMS groups $(p>0.05)$.

\section{Experimental task}

Participants performed an OCD-specific emotion regulation task during fMRI scanning (see Fig. $1 b$ and Supplementary Method S1.2 for additional details regarding task design and stimulus selection). Subjective distress ratings for each condition were used as behavioral outcome measures.

\section{Statistical analysis}

Group differences in demographics, clinical measures and task-related measures between patients and controls overall, and real rTMS and sham rTMS subsamples 
were analyzed with SPSS v. 15 (SPSS Inc., USA). Since the distress rating data did not meet parametric assumptions, planned repeated-measures analyses of variance (ANOVAs) could not be performed. We therefore analyzed the data with non-parametric tests. Results were considered significant at $p<0.05$ after Bonferroni correction for the number of comparisons per investigated effect; trends were set at $0.05<p<0.10$.

To assess emotion provocation at baseline we computed mean distress ratings collapsed over instruction [fear distress rating $=($ fear attend + fear regulate $) / 2$; OCD distress rating $=(\mathrm{OCD}$ attend $+\mathrm{OCD}$ regulate $) / 2]$. The fear, $\mathrm{OCD}$ and the neutral distress ratings were entered in a Friedman's ANOVA per group to assess within-group effects of picture type. This ANOVA was followed up by Wilcoxon signed-rank tests comparing fear distress $v$. neutral and OCD distress $v$. neutral within groups (Bonferroni correction $p<0.05 / 2$ ). Mann-Whitney tests compared the mean fear, mean OCD and neutral distress ratings between the groups to assess differences in emotion provocation (Bonferroni correction $p<0.05 / 3$ ).

To assess emotion regulation at baseline we computed the mean score for the attend and regulate instructions over all conditions [attend $=($ fear attend $+\mathrm{OCD}$ attend $) / 2 ;$ regulate $=($ fear regulate $+\mathrm{OCD}$ regulate $) / 2]$. To assess within-group instruction effects, these overall attend and regulate scores (main effect; $p<0.05$ ), as well as, the attend and regulate distress ratings per picture type (fear, OCD; $p<0.05 / 2$ ) were compared with Wilcoxon signed-rank tests. We computed fear difference and OCD difference scores as a measure of emotion regulation (fear difference $=$ fear attend - fear regulate; OCD difference $=$ OCD attend - OCD regulate). These difference scores were compared between the groups with Mann-Whitney tests $(p<0.05 / 2)$.

In the exact same manner we analyzed emotion regulation task performance after rTMS (performance during scan 2) between the groups of real $(10 \mathrm{~Hz})$ and sham $(10 \mathrm{~Hz})$ OCD patients and between real $(1 \mathrm{~Hz})$ and sham $(1 \mathrm{~Hz})$ controls, respectively. Additionally, given our fixed-order repeated-measures design, we compared distress ratings of scans 1 and 2 within groups with Wilcoxon signed-rank tests $(p<0.05 / 4)$, and we calculated change scores between distress ratings of scan 1 and those of scan 2 and compared them between the groups with Mann-Whitney tests $(p<0.05 / 4)$.

Spearman's rho was used to assess correlations between clinical variables (YBOCS, MADRS, ERQ) and reappraisal performance (the difference between attend minus regulate distress ratings) in patients.

\section{fMRI analyses}

Functional gradient echo-planar and structural T1-weighted imaging was performed on a GE Signa
HDxt 3.0-T MRI scanner (General Electric, USA). See Supplementary Method S1.3.1 for imaging acquisition parameters and preprocessing steps. To probe the blood-oxygen-level dependent (BOLD) response related to emotion processing and regulation during scans 1 and 2, different subject-level and group-level analyses were performed (see also Supplementary Method S1.3.2). In all first-level analyses nine regressors of interest contained the onsets of the pictures [neutral attend, fear attend/regulate, OCD (wash/ check/symmetry) attend/regulate]. Regressors of no interest comprised the rating scales and instruction periods (boxcars, duration $=5 \mathrm{~s}$ and $3 \mathrm{~s}$ ) and the participants' movement parameters. Fixation periods remained unmodeled as a low-level implicit baseline. A high-pass filter (128 s cut-off period) was used to remove noise associated with low-frequency confounds. All second-level group comparisons were masked by relevant within-group effects at $p<0.05$ uncorrected. Since in this study we were interested in what is common to all OCD patients and since most patients appeared to have mixed symptoms, OCD-related contrasts were averaged over all OCD stimuli.

In Analysis 1 we assessed emotion provocation at baseline. To accurately model the fast limbic response associated with emotion processing and account for possible differences in hemodynamic response function (HRF) shape between brain regions and study groups (Larson et al. 2006; Caseras et al. 2010; Waugh et al. 2010), conditions at the participant level were entered as delta functions and convolved with both the canonical HRF and its time and dispersion derivatives. Contrast images containing parameter estimates for comparisons of interest were subsequently entered into a second-level mixed ANOVA with group [OCD patients $(N=43)$; controls $(N=38)]$ as betweenparticipant factors and picture type (fear $>$ neutral; OCD-related $>$ neutral), and HRF regressor (3) as within-participant factors to assess effects of group and group $\times$ picture type interactions.

In Analysis 2 we assessed emotion regulation at baseline. Since reappraisal is characterized by an early recruitment of control areas (Goldin et al. 2008, 2009a, b. Hermann et al. 2009; Lang et al. 2012), the $10 \mathrm{~s}$ stimuli were split in an early (1st $5 \mathrm{~s}$ ) and late (6-10 s) boxcar per condition. These boxcars were convolved with the canonical HRF. At the participant level, regulation was thus contrasted with attend per picture type (fear regulate $>$ attend; OCD-related regulate $>$ attend) for the early time bin only. We assessed main effect of task over all subjects $(N=81)$ in a mixed ANOVA with group (patients, controls) and picture type (fear regulate $>$ attend; OCD-related regulate $>$ attend). Since regulation of OCD-related stimuli seemed behaviorally relevant for patients only, group 
comparisons were subsequently performed per picture type (fear regulate $>$ attend; OCD-related regulate $>$ attend) using two-sample $t$ tests. Analyses of covariance were performed between reappraisal performance (the difference between attend and regulate distress ratings) and YBOCS severity score (patients only) on regulation-related BOLD response at baseline (contrasts: fear or OCD-related regulate $>$ attend).

Analysis 3 probed the effects of real $v$. sham rTMS on emotion regulation within OCD patients [real (10 $\mathrm{Hz}): N=19$; sham $(10 \mathrm{~Hz}): N=20$ ] and controls [real (1 Hz): $N=19$; sham $(1 \mathrm{~Hz}): N=18$ ]. Because of our fixed-order repeated-measures design our rTMS analysis was two-fold. Two-sample $t$ tests were performed between the real and sham rTMS groups on day 2 for the BOLD response related to the general process of picture appraisal regardless of instruction conditions (condition-independent contrast: all pictures $>$ fixation) and for emotion regulation contrasts: (fear regulate $>$ attend; OCD-related regulate $>$ attend). Additionally, group $\times$ session effects were assessed, by comparing the sham rTMS and real rTMS groups on subject-level change contrasts over sessions (all pictures $>$ fixation, day $1>2$; fear or OCD-related regulate $>$ attend, day $1>2)$.

Imaging results were considered significant when controlled for type I errors after small-volume familywise error (FWE) correction (Worsley et al. 1996) with a $10 \mathrm{~mm}$-radius sphere in a priori regions of interest (ROIs) concerning the ventral-dorsal emotion regulation circuitry (i.e. amygdala, rACC, dlPFC and dmPFC as assessed with the WFU Pick atlas; Maldjian et al. 2003) Bonferroni-corrected for the number of ROIs ( $p_{\text {FWE-SVC }}$ $<0.0125)$ after image-thresholding at $p<0.001$ uncorrected. Whole-brain voxel-wise FWE-corrected results are reported as well. Given that this is the first report of emotion regulation in OCD and the exploratory nature of our TMS experiment (Volman et al. 2011), additional results are reported for exploratory purposes at $p<0.001$ uncorrected (Lieberman \& Cunningham, $2009)$ and a minimum cluster-extent $\left(k_{\mathrm{e}}\right)$ of 3 voxels as well.

To specifically test for regulation-related changes in frontal-amygdala connectivity between the groups (Goldin et al. 2013) we performed a post-hoc general psycho-physiological interaction (gPPI) (McLaren et al. 2012), using the left $\mathrm{dmPFC}$ as a seed region (sphere with $10 \mathrm{~mm}$ radius around coordinate of main effect: $x / y / z=-9 / 8 / 64$; chosen since it was recruited during emotion regulation in both groups) and the bilateral amygdala as ROI. With gPPI all relevant task conditions and interactions can be modeled simultaneously, resulting in better model fit compared with traditional PPI (McLaren et al. 2012). At baseline dmPFC connectivity on the fear regulate $>$ attend contrast was compared in a second-level $t$ test in SPM. To assess how rTMS affected dmPFC-amygdala connectivity, we used the MarsBar toolbox (http:// marsbar.sourceforge.net) to extract mean beta values in bilateral amygdala (see Supplementary Results S2.2) on scans 1 and 2 in the real and sham rTMS groups and performed a repeated-measures ANOVA in SPSS with rTMS group as between-subject factor, session as within-subject factor, and the change in fear attend distress ratings over sessions as a covariate.

\section{TMS protocol}

Offline rTMS was applied using a hand-held statically cooled figure-of-eight TMS coil (Medtronic MagOption) under guided real-time neuronavigation (Visor v. 1.0, Eemagine $\mathrm{GmbH}$, Germany). Participants were randomly assigned to the real (dlPFC) or sham (vertex) rTMS condition. Coordinates for stimulation in the active condition were based on a participant-specific functionally derived hot-spot (Sack et al. 2009; see Fig. 1a and Supplementary Method S1.4 for hot-spot definition and localizations). In the active (dlPFC) condition, patients ('therapy model') received $10 \mathrm{~Hz}$ rTMS over left dlPFC at $110 \%$ of resting motor threshold during $20 \mathrm{~min}$ in 30 10-s trains with a 30-s inter-train-interval (Conca et al. 2002), which resulted in 3000 pulses in total. Controls ('virtual lesion model $^{\prime}$ ) in the active dlPFC condition received $1 \mathrm{~Hz}$ rTMS for $20 \mathrm{~min}$ (Rossi et al. 2009; Siebner et al. 2009), resulting in 1200 pulses in total. In the sham condition, the protocol was similar to the active condition of patients $(10 \mathrm{~Hz})$ and controls $(1 \mathrm{~Hz})$, respectively, except that the coil localization was $\sim 2 \mathrm{~cm}$ behind the vertex. Participants were naive to rTMS and blind to stimulation condition.

\section{Results}

\section{Emotion regulation task performance in OCD}

At baseline (see Fig. 2a; Supplementary Table S1), distress ratings in patients compared with controls were higher for fear $(U=417, p<0.001)$ and OCD stimuli $(U=236, p<0.001)$, but not neutral stimuli $(p>0.1)$. There was a significant within-group effect of picture type [OCD: $F_{\mathrm{r}}(2,40)=68.0, p<0.001$; controls: $F_{\mathrm{r}}(2,35)$ $=50.4, p<0.001$ ], due to fear stimuli (OCD: $Z=-5.6, p$ $<0.001$; controls: $Z=-4.5, p<0.001)$ and OCD stimuli (OCD: $Z=-5.5, p<0.001$; controls: $Z=-3.5, p<0.001$ ) being rated significantly more distressing than neutral stimuli.

When comparing the fear and OCD difference scores, the groups did not differ in fear regulation $(p>0.1)$, but patients compared with controls had a significantly larger regulation effect on OCD-related stimuli $(U=545, p<0.01)$. There was a main effect of 
instruction collapsed over picture types in both groups with distress ratings being higher in the attend $v$. the regulate condition (OCD: $Z=-3.6, p<0.001$; in controls this was at trend-level: $Z=-1.9, p=0.06$ ). In patients the instruction effect was significant in both the fear and OCD-related stimuli (both $p<0.005$ ), whereas in controls it was present in fear $(p=0.057$; trend) but not OCD-related $(p>0.3)$ stimuli.

In patients, YBOCS, but not MADRS, score correlated with ERQ reappraisal [YBOCS: $r_{s}(\mathrm{df}=41)=-0.50$, $p=0.001$; MADRS: $\left.r_{s}(\mathrm{df}=41)=-0.23, p=0.13\right]$. YBOCS and MADRS scores did not significantly correlate with fear or OCD-related reappraisal success (difference scores) or with ERQ-suppression scores $\left[r_{s}(\mathrm{df}=41)<0.23\right.$, $p>0.14]$.

\section{Neural correlates of emotion regulation in OCD}

During emotion provocation (main effect of group) and especially during processing of disease-relevant stimuli (group $\times$ picture type interaction) OCD patients compared with controls showed an increased amplitude and/or altered timing of the BOLD response in the right amygdala $\left(x / y / z=27 /-4 /-17, Z=3.9, k_{\mathrm{e}}=21\right.$, $\left.p_{\mathrm{FWE}-\mathrm{SVC}}=0.004\right)$ and occipital cortex at the uncorrected level (Supplementary Fig. S1, panels A and B and Supplementary Results S2.1).

During emotion regulation (see Fig. $2 b$, panels A and B), patients compared with controls showed decreased activity in left dlPFC ( $p_{\mathrm{FWE}-\mathrm{SVC}}=0.009$; fear regulation) and increased dmPFC activity ( $p_{\text {FWE-SVC }}=0.001$; OCDrelated regulation). Analysis of main effect of task showed that over all participants $(N=81$; Supplementary Fig. S1, panel C) and stimuli, reappraisal was associated with increased dmPFC and decreased rACC activity $\left(p_{\text {FWE-SVC }}<0.005\right)$. Within-group analyses (see Table 2, Supplementary Fig. S1, panel D) showed that emotion regulation was characterized by recruitment of bilateral dIPFC and left dmPFC in controls (fear regulation) and by left dmPFC activity in patients (OCD-related regulation).

In controls, activity of the right dlPFC $[\mathrm{rho}(\mathrm{df}=36)=$ $0.48 ; \mathrm{x} / \mathrm{y} / \mathrm{z}=30 / 35 / 28, \mathrm{Z}=3.8, \mathrm{BA} 9 / 36, k_{\mathrm{e}}=19, p_{\text {FWE-SVC }}$ $=0.004]$ was associated with greater reduction of fear distress during fear regulation. In patients regulation success did not correlate with brain activity. Disease severity, however, correlated inversely with regulation-related activity in bilateral dmPFC $\left(p_{\mathrm{FWE}-\mathrm{SVC}}=0.002\right)$ and thalamus $\left(p_{\mathrm{FWE}}=0.04\right.$; see Fig. $2 b$, panel C, Supplementary Table S3).

Post-hoc analyses showed that OCD patients with $(N=24)$ and without $(N=19)$ co-morbid diagnoses did not differ significantly on demographics, clinical data, baseline task performance (all $p>0.05$ ), or brain activity during emotion regulation (data not shown).

\section{Emotion regulation after rTMS}

First, we compared groups during scan 2 (see Supplementary Table 4a). Single-session dIPFC rTMS was able to modulate dorsal frontal brain activity when we assessed the BOLD response related to the general process of picture appraisal regardless of instruction condition (condition-independent contrast): we observed sham-controlled excitation after HF rTMS in patients (left dmPFC: $p_{\mathrm{FWE}-\mathrm{SVC}}=0.002$; right dIPFC: $\left.p_{\text {FWE-SVC }}=0.004\right)$ and inhibition after LF rTMS in controls (left dlPFC $p_{\text {FWE-SVC }}=0.08$, subthreshold). When assessing the effects of rTMS on emotion regulation specifically in controls, real $v$. sham LF rTMS did not affect ROI activity, but was at the uncorrected level associated with increased hippocampal activity. Patients receiving sham $v$. real HF rTMS had significantly increased dmPFC activity $\left(p_{\text {FWE-SVC }}=0.009\right)$ and the uncorrected level, increased parahippocampal and opercular activity during emotion regulation. Task performance during scan 2 was not significantly different between the real $v$. sham rTMS groups (see Supplementary Table S2a, b; Supplementary Fig. S2).

Second, real $v$. sham rTMS did not significant affect the relative change in task performance over sessions (see Supplementary Table S2a, b; Supplementary Fig. S2). In controls after sham LF rTMS the fear attend distress rating was reduced during session 2 compared to session $1(p=0.01)$. This was not the case after real LF rTMS $(p=0.51)$, and the between-group (sham $v$. real LF rTMS) interaction effects was not significant $(p=0.21)$. In patients the fear attend change score showed opposing effects, with a near-trend decrease in fear distress over sessions in patients after real HF rTMS $(p=0.11)$, a lack of decrease in the sham HF rTMS group $(p=0.74)$, and a non-significant group interaction $(p=0.17)$. When comparing the relative change in brain activity from session 1 to session 2, the real HF $v$. sham HF patients showed a relative decrease of dmPFC $\left(p_{\mathrm{FWE}-\mathrm{SVC}}=0.001\right)$ and, at the uncorrected level, occipital cortex, activity on the condition-independent contrast (see Fig. 3 and Supplementary Table S4a, b for all additional rTMS results). The real LF $v$. sham LF controls showed no significant ROI-corrected results over sessions. At the uncorrected level we found a relative increase of visual processing area activity on the condition-independent contrast. Post-hoc analysis showed that the changes in fear attend distress ratings correlated with relevant ROI brain activity (Supplementary Results S2.2).

\section{Post-hoc frontal-limbic connectivity analyses}

Results from the gPPI analysis showed that at baseline OCD patients, compared with controls, had less dmPFC-bilateral amygdala connectivity $\left(p_{\text {FWE-SVC }}<\right.$ 
(b)

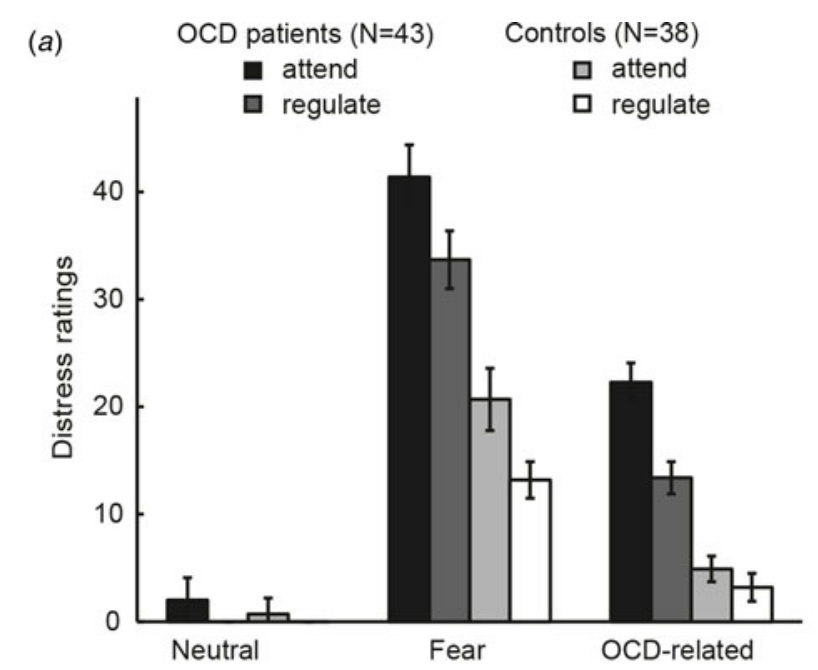

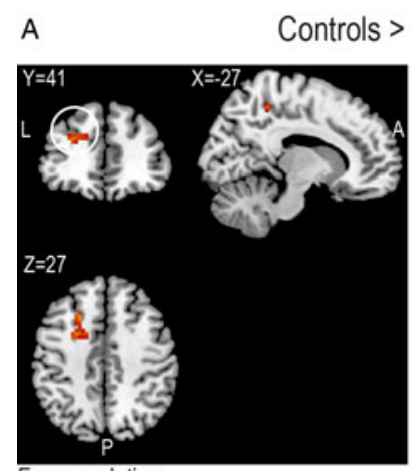

Fear regulation
Controls $>\mathrm{OCD}$ patients

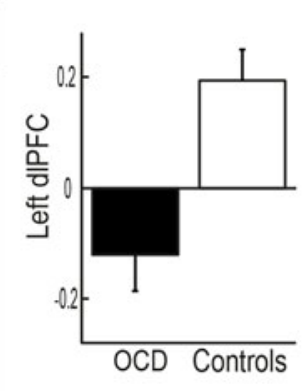

B

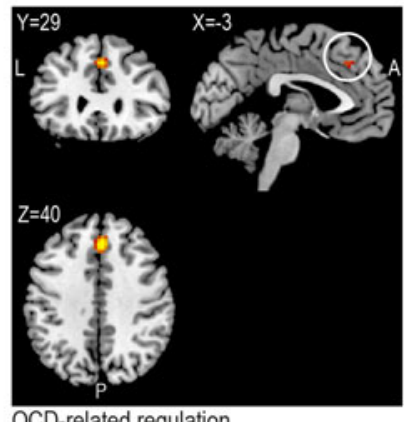

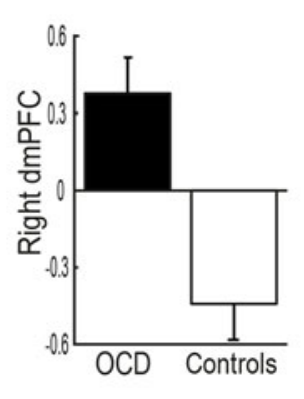

C Regression with disease severity score in OCD patients

D

Controls > OCD patients
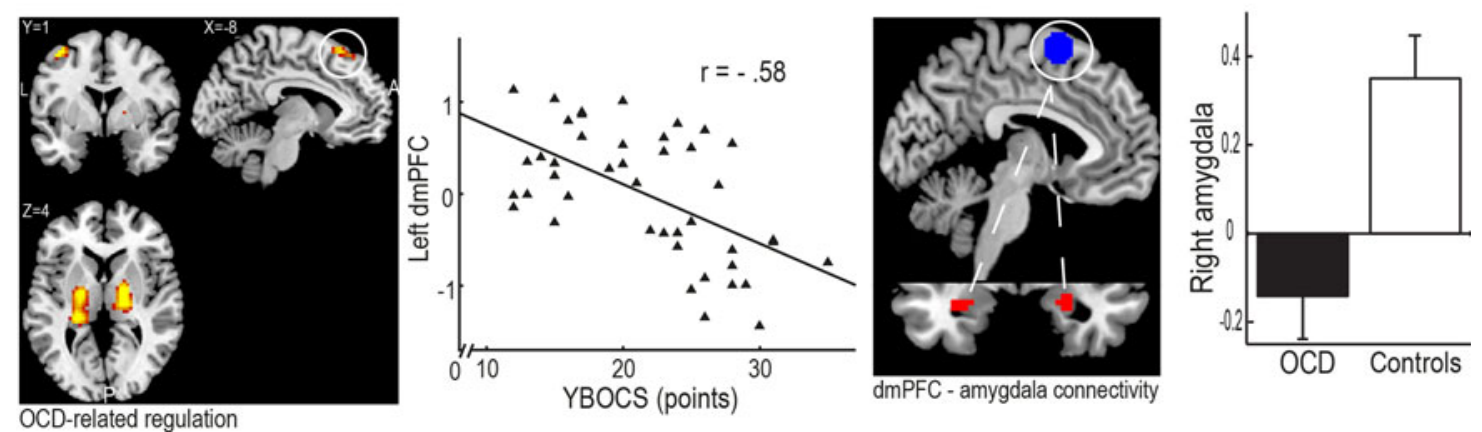

Fig. 2. (a) Baseline emotion regulation task performance. Bar graph depicting the mean ( \pm standard error of the mean; S.E.M.) self-report distress rating per condition. (b) Neural correlates of emotion regulation at baseline (scan 1). Panel A. Decreased activity in left dlPFC $\left(x / y / z=-27 / 41 / 25, Z=3.5, k_{\mathrm{e}}=42\right)$ in OCD patients $(N=43) v$. controls $(N=38)$ during fear regulation at baseline (contrast: fear regulate > attend). Left: Left dIPFC cluster from two-sample $t$ test. Right: Parameter estimates of peak left dlPFC voxel in patients (black) and controls (white). At $p<0.001$ whole-brain uncorrected level the dlPFC cluster also extends through BA $6 / 8\left(\mathrm{x} / \mathrm{y} / \mathrm{z}=-21 / 17 / 40, k_{\mathrm{e}}=159, \mathrm{Z}=3.9\right)$, and additional findings are left inferior parietal cortex $(\mathrm{x} / \mathrm{y} / \mathrm{z}$ $\left.=-48 /-31 / 22, Z=3.8, k_{\mathrm{e}}=13\right)$, right precuneus $\left(\mathrm{x} / \mathrm{y} / \mathrm{z}=15 /-43 / 52, Z=3.5, k_{\mathrm{e}}=12\right)$, left precentral gyrus $(\mathrm{x} / \mathrm{y} / \mathrm{z}=-45 /-4 / 25$, $Z=3.2$, BA 9, $\left.k_{\mathrm{e}}=3\right)$ and right superior frontal gyrus $\left(\mathrm{x} / \mathrm{y} / \mathrm{z}=21 / 26 / 37, Z=3.2, \mathrm{BA} 8, k_{\mathrm{e}}=3\right)$. Panel B. Increased dmPFC activity $\left(\mathrm{x} / \mathrm{y} / \mathrm{z}=3 / 32 / 40, Z=4.1, k_{\mathrm{e}}=40\right)$ in OCD patients $(N=43) v$. controls $(N=38)$ during OCD-related regulation at baseline (contrast: OCD-related regulate> attend). Left: Significant cluster in right dmPFC from two-sample $t$ test. Right: Parameter estimates of peak right dmPFC voxel in patients (black) and controls (white). At the $p<0.001$ uncorrected level an additional finding is the right anterior frontal cortex $\left(x / y / z=27 / 59 / 1, B A 10, Z=3.5, k_{\mathrm{e}}=4\right)$. $t$ values are displayed from $t=3.2$ (threshold, red) to maximum (yellow; $t=4.1$ ). Panel C. Left: $t$ statistic image of regression analysis between Yale-Brown Obsessive Compulsive Scale (YBOCS) and brain activity during OCD-related regulation patients at baseline. Significant results in right 
Table 2. Main effect of emotion regulation within controls and patients per picture type at baseline (scan 1)

\begin{tabular}{|c|c|c|c|c|c|c|c|c|}
\hline & \multirow[b]{2}{*}{ BA } & \multirow[b]{2}{*}{ Side } & \multirow[b]{2}{*}{$k_{\mathrm{e}}$} & \multicolumn{3}{|c|}{ MNI coordinates } & \multirow[b]{2}{*}{ Z } & \multirow[b]{2}{*}{$p_{\text {FWE-SVC }}$} \\
\hline & & & & $\mathrm{x}$ & $\mathrm{y}$ & $\mathrm{z}$ & & \\
\hline \multicolumn{9}{|l|}{ Controls $(N=38)$} \\
\hline \multicolumn{9}{|l|}{ Contrast: fear regulate $>$ attend } \\
\hline \multirow[t]{3}{*}{ Dorsolateral prefrontal cortex } & $9 / 10 / 46$ & $\mathrm{R}$ & 53 & 33 & 44 & 37 & 4.11 & $0.001^{*}$ \\
\hline & & & & 27 & 38 & 31 & 3.51 & \\
\hline & & $\mathrm{L}$ & 2 & -30 & 41 & 25 & 3.15 & 0.025 \\
\hline Postcentral gyrus & 4 & $\mathrm{~L}$ & 31 & -48 & -10 & 52 & 3.94 & - \\
\hline \multirow[t]{2}{*}{ Dorsomedial prefrontal cotex (ACC/pre-SMA) } & $24 / 6$ & $\mathrm{~L}$ & 13 & -15 & 2 & 43 & 3.66 & $0.006^{*}$ \\
\hline & & & 2 & -9 & 5 & 58 & 3.14 & \\
\hline \multirow[t]{2}{*}{ Inferior frontal gyrus } & 44 & $\mathrm{~L}$ & 21 & -51 & 5 & 22 & 3.65 & - \\
\hline & & $\mathrm{R}$ & 3 & 45 & 11 & 10 & 3.19 & - \\
\hline Middle frontal gyrus & 8 & $\mathrm{~L}$ & 25 & -21 & 20 & 46 & 3.54 & - \\
\hline \multicolumn{9}{|l|}{ Contrast: OCD-related regulate > attend: N.S. } \\
\hline \multicolumn{9}{|l|}{ OCD patients $(N=43)$} \\
\hline \multicolumn{9}{|l|}{ Contrast: fear regulate $>$ attend: $N . S$. } \\
\hline \multicolumn{9}{|l|}{ Contrast: $O C D$-related regulate $>$ attend } \\
\hline \multirow[t]{2}{*}{ Dorsomedial prefrontal cortex (SMA) } & 6 & $\mathrm{~L}$ & 43 & -6 & -1 & 70 & 3.59 & $0.007^{*}$ \\
\hline & & & & -9 & 8 & 64 & 3.33 & \\
\hline \multirow[t]{3}{*}{ Caudate nucleus/Putamen } & N.A. & $\mathrm{R}$ & 9 & 18 & 17 & 4 & 3.54 & - \\
\hline & & $\mathrm{L}$ & 3 & -18 & 2 & 7 & 3.39 & - \\
\hline & & $\mathrm{L}$ & 2 & -15 & 14 & 7 & 3.10 & - \\
\hline \multirow[t]{2}{*}{ Middle temporal gyrus } & 21 & $\mathrm{~L}$ & 13 & -51 & -34 & -8 & 3.37 & - \\
\hline & & & 3 & -57 & -9 & -8 & 3.21 & - \\
\hline Frontal operculum inferior & 44 & $\mathrm{~L}$ & 4 & -57 & 8 & 10 & 3.31 & - \\
\hline Anterior insula & 13 & $\mathrm{R}$ & 3 & 39 & 14 & 7 & 3.19 & - \\
\hline
\end{tabular}

BA, Brodmann Area; ACC, anterior cingulate cortex; N.s., not significant; SMA, supplementary motor area.

One-sample $t$ tests per group per contrast. Results are corrected for multiple comparisons at the voxel-level $\left({ }^{*} p_{\mathrm{FWE}-\mathrm{SVC}}<0.0125\right.$; trends $\left.p_{\mathrm{FWE}-\mathrm{SVC}}<0.025\right)$ in a priori regions-of-interest by small-volume correction with $10 \mathrm{~mm}$ sphere after thresholding at $p<0.001$ uncorrected. Exploratory whole-brain results are presented at $p<0.001$ uncorrected with a minimal cluster extent of 3 .

0.0125; Fig. 2b, panel D). Repeated-measures ANOVA with factors rTMS group (real $v$. sham) and session (scan 1 v. 2) showed altered dmPFC-amygdala connectivity after real rTMS compared with sham in OCD patients $(r T M S \times$ session interaction effect at trend-level in left amygdala $[F(36,1)=3.7, p=0.06$; right amygdala $=$ N.s.: $p=0.22)$ ]. This interaction effect was due to dmPFC-left amygdala connectivity showing opposing effects after real TMS (mean beta day 1 $=0.06$; day $2=-0.18$ ) compared to sham rTMS (mean beta day $1=-0.06$; day $2=0.18)$. There were no significant effects in controls (all $p>0.3$ ).

\section{Discussion}

To our knowledge this is the first study assessing the neural correlates of effortful emotion regulation in OCD patients $v$. healthy controls. Further, this is also the first study to experimentally probe the differential modulatory

thalamus $(Z=4.5)$ and left $\operatorname{dmPFC}(Z=4.0)$. Image is thresholded at $p<0.001$ whole-brain uncorrected. $t$ values are displayed from red $(t=3.3$ threshold) to yellow $(t>4.5)$. Middle/right: Scatter plot of parameter estimate of left dmPFC peak voxel and disease severity. Panel D. Decreased dmPFC-amygdala connectivity in patients $v$. controls during fear regulation (contrast: fear regulate > attend). Left: Top: seed region in dmPFC [blue; $10 \mathrm{~mm}$ sphere around $(\mathrm{x} / \mathrm{y} / \mathrm{z}=-9 / 8 / 64)]$. Bottom: Results from two-sample $t$ test of general psycho-physiological interaction analysis [red; right amygdala $\left(\mathrm{x} / \mathrm{y} / \mathrm{z}=24 /-7 /-20, z=3.4, k_{\mathrm{e}}=3\right)$; left amygdala $\left.\left(\mathrm{x} / \mathrm{y} / \mathrm{z}=-33 /-10 /-23, Z=3.4, k_{\mathrm{e}}=15\right)\right]$. For illustration purposes image is thresholded at $p<0.005$ uncorrected. Right: Parameter estimate of right amygdala peak voxel. S, Superior; P, posterior; L, left; A, anterior; $r$, Pearson's rho; $k_{\mathrm{e}}$ cluster extent; dlPFC, dorsolateral prefrontal cortex; dmPFC, dorsomedial prefrontal cortex; All parameter estimates are in arbitrary units. Error bars represent S.E.M. 
(a)

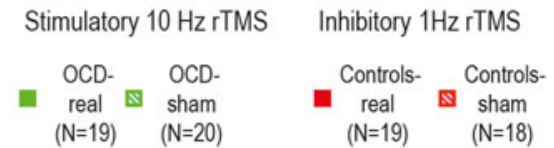

(b)
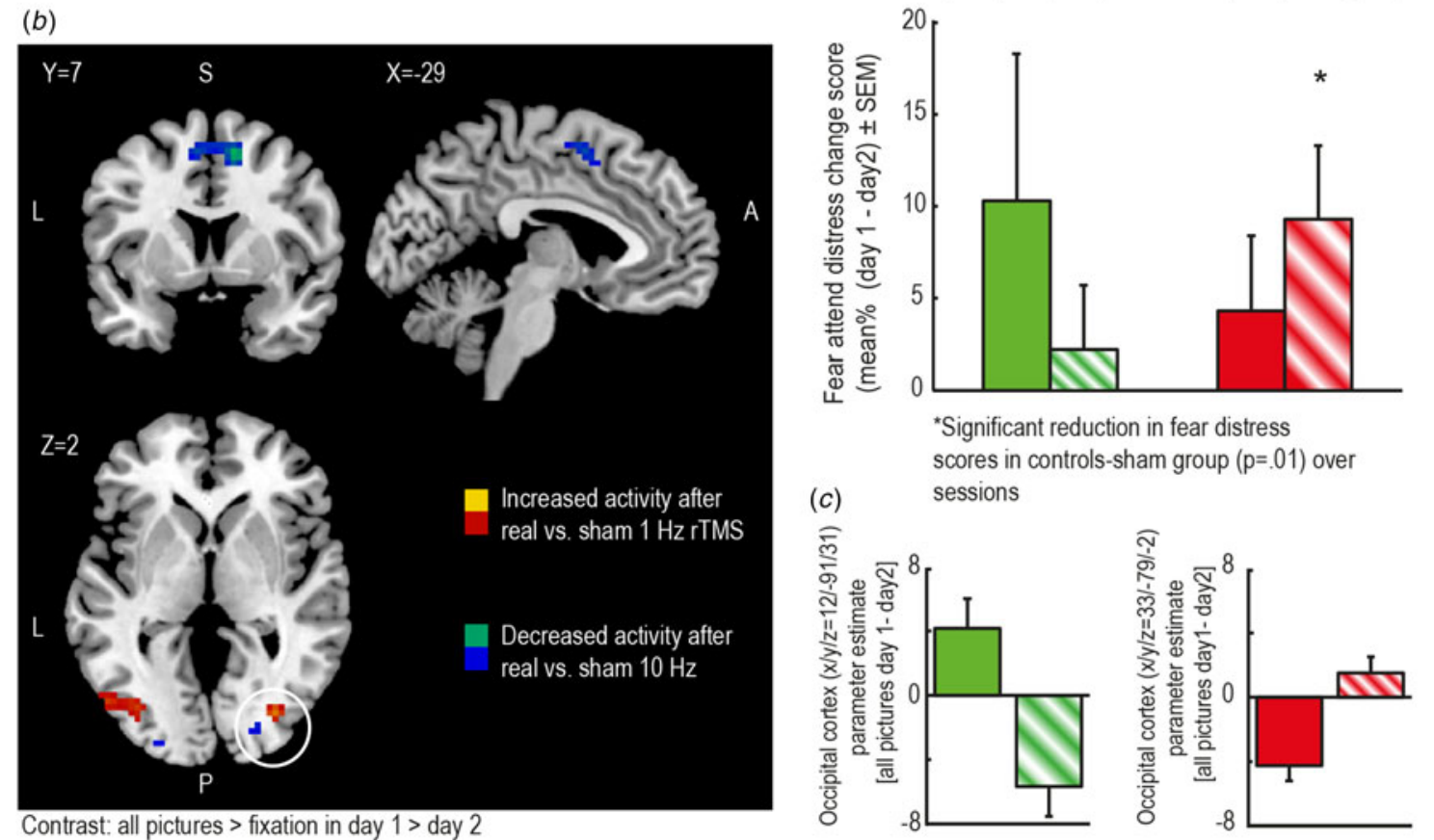

Fig. 3. Differential effects of real $v$. sham high-frequency $(10 \mathrm{~Hz})$ and low-frequency $(1 \mathrm{~Hz})$ left dlPFC repetitive transcranial magnetic stimulation (rTMS) on the change of fear distress ratings and brain activity from scan 1 to scan 2. (a) Bar graph depicting decrease of fear attend distress ratings from day 1 to day 2 after real (dlPFC) $v$. sham (vertex) stimulatory (10 Hz; OCD patients) and inhibitory (1 Hz; controls) rTMS. Within-group fear attend distress reductions (day 1-day 2$)$ as tested with Wilcoxon-signed rank tests: $\mathrm{OCD}$ real $(Z=-1.6, p=0.11)$; OCD sham $(Z=0.3, p=0.74)$; controls real $(Z=-0.7, p=0.51)$; controls sham $\left(Z=-2.4 ;{ }^{*} p=0.01\right)$. Between-group (real $v$. sham) effects were not significant $(p>0.1)$. $(b) t$ statistic image, for illustration purposes thresholded at $p<0.005$ uncorrected; $t$ values are displayed from red $(t=2.7$, controls) and blue $(t=2.7$, patients) to yellow/green $(t>5.0)$. (c) Parameter estimate plot of the change of visual cortex activity in OCD patients (left) and controls (right) after rTMS. dlPFC, dorsolateral prefrontal cortex; \%, percentage; error bars represent S.E.M.; parameter estimates are in arbitrary units.

effects of sham-controlled HF and LF single-session rTMS over left dIPFC on emotion processing and regulationrelated brain activity in OCD patients and controls.

\section{Emotional reactivity}

OCD patients showed increased self-reported distress and abnormal activity in the amygdala and occipital cortex during processing of disease-related and general fear stimuli. This converges with prior findings of involvement of these regions in the processing of emotional intensity (Waugh et al. 2010), and replicate findings of increased emotional reactivity in generally smaller samples of (often medicated) OCD patients (van den Heuvel et al. 2004; Rotge et al. 2008). Deviant timing of amygdala responses in OCD patients corroborates findings in spider phobics (Larson et al. 2006). Accounting for such changes may increase sensitivity of data analysis, since timing rather than amplitude of the BOLD response may be altered in psychopathology (Caseras et al. 2010; Waugh et al. 2010).

\section{Emotion regulation}

Although distress ratings to general fearful and OCD-related stimuli were significantly higher in OCD patients than controls, even in the regulation condition, the groups showed similar rates of distress reduction after reappraisal. At the neural level, patients and controls showed overlapping as well as distinct recruitment of known emotion regulation brain areas (Kalisch, 2009). Both groups recruited the $\mathrm{dmPFC}$ during emotion regulation. Only controls recruited bilateral dIPFC, and this was related to reduction of fear distress, underscoring the behavioral relevance of the dorsal PFC for emotion regulation in healthy participants (Drabant et al. 2009). 
Cognitive reappraisal was not associated with downregulation of amygdala activity, which may be due to the fast and short-lasting response in this region (Hermann et al. 2009). Reappraisal, however, was in both groups associated with decreased rACC activity. The rACC is part of the ventral emotion processing system (Phillips et al. 2003a), is structurally and functionally connected with the amygdala during emotional reactivity (Pezawas et al. 2005; Ghashghaei et al. 2007), and has been related to selfmonitoring of negative affect (Ochsner et al. 2004).

Overall, our data show that when cued within the context of an experiment, patients with OCD can implement reappraisal as a cognitive-linguistic strategy to down-regulate negative affect. When doing so, however, OCD patients compared with controls showed less recruitment of the dlPFC, less dmPFC-amygdala connectivity (during fear regulation), and enhanced recruitment of dmPFC (during OCD-related regulation). Such dissociation of finding different reappraisalrelated brain activity between psychiatric patients and controls under similar task performance has been reported before (Goldin et al. 2009a; Kanske et al. 2012), and underscores the added value of fMRI to detect changes in emotion regulation mechanisms in OCD. Diminished dIPFC and frontal-limbic connectivity during reappraisal-mediated down-regulation of negative affect in OCD is in accordance with emotion regulation studies in anxiety and depression (Goldin et al. 2009a; New et al. 2009; Erk et al. 2010) and with findings during executive functioning in OCD (van den Heuvel et al. 2005a; Remijnse et al. 2006; de Vries et al. 2014). Emotion regulation-related dlPFC activity has been associated with sustained amygdala down-regulation in controls (Erk et al. 2010), and combined with the finding of diminished dmPFC-amygdala connectivity, our data suggests that this hypoactivity of the dIPFC may reflect diminished ability of patients to control pathological anxiety in everyday life over longer stretches of time. Differential recruitment of regulatory brain regions in patients (dmPFC) and controls (dIPFC) could also be related to the use of different regulation strategies (Kanske et al. 2012). Although not an a priori ROI, we observed parietal hypoactivity during fear regulation in patients as well. In the context of the wider OCD literature (Menzies et al. 2008; de Wit et al. 2012), our data suggest that impaired cognitive control in OCD is related not only to dysfunction of the dorsal PFC but to a wider distributed frontal-parietal network.

Interpretation of the observed dmPFC hyperactivity in OCD patients during OCD-specific reappraisal is not straightforward, due to the absence of a direct association between the behavioral and neural level in patients. Also, in controls reappraisal did not significantly affect distress ratings or brain activity during
OCD-related stimuli, probably related to the low emotional relevance of OCD-related stimuli for healthy participants. We cannot rule out, however, that dmPFC hyperactivity is an indication of a compensatory mechanism in patients related to frontal-parietal failure. OCD patients overall, and especially those with higher disease severity, reported less use of cognitive reappraisal to modulate emotions in everyday life. Additionally, greater disease severity was related to less recruitment of dorsal regulation-related brain areas (including the $\mathrm{dmPFC}$ ) and less rACC downregulation (trend) during emotion regulation. This suggests that only patients that are less affected by the disease are able to use reappraisal in the context of the experiment as well as in everyday life, which seems in line with the hypothesis that reduced cognitive control over (para)limbic regions is at least a contributing mechanism in OCD pathophysiology.

\section{Neuromodulatory effects of repetitive transcranial magnetic stimulation}

In the present study we set out to assess if high-frequency rTMS over the left dIPFC would boost regulatory control in OCD patients, and if low-frequency dIPFC rTMS would decrease emotion regulation capabilities in controls. The data show that stimulatory high-frequency rTMS resulted in a condition-independent increase in dorsal frontal activity, and conversely inhibitory low-frequency rTMS in a reduction of dIPFC activity. rTMS did not significantly affect task performance during scan session 2. An interpretation of the observed differences in brain activity we specifically observed during emotion regulation on scan 2 may be that inhibition in controls resulted in increased task-related cognitive effort (increased hippocampal activity) and stimulation in patients induced increased task-related neural efficiency (with relatively reduced dorsal frontal activity on the emotion regulation contrast compared to the sham condition).

Further, LF and HF rTMS may have differentially affected the change in emotional saliency network activity over sessions in patients and controls. Reduced fear distress over sessions in the real $v$. sham HF rTMS patient group was associated with decreased brain activity in visual emotion processing areas (occipital cortex, rACC, amygdala) and with alterations in dmPFC-amygdala connectivity. By contrast, in the real LF control group, relatively increased fear distress over sessions was associated with increased visual processing related (occipital cortex) brain activity.

Overall, our rTMS findings are in line with other reports of frontal rTMS effects on local as well as distant connected brain regions (van der Werf et al. 2010; Reithler et al. 2011; Volman et al. 2011; van den Heuvel et al. 2013). Our results seem to indicate that dlPFC 
rTMS affected more automatic (condition-independent) rather that effortful (reappraisal task specific) regulatory processes (Gyurak et al. 2011). We speculate that HF rTMS over dIPFC may thus be beneficial for fear extinction learning, an implicit regulatory process that is known to be deficient in OCD (Milad et al. 2013).

\section{Limitations and strengths}

A limitation of this study is that, unlike previous studies in anxiety (Goldin et al. 2009b; Hermann et al. 2009), comparison of disease-specific $v$. disease-unrelated emotion regulation was hampered by the absence of sufficient emotion induction of OCD-related stimuli in the control group. Nonetheless, comparison of fear regulation across the groups enabled us to assess general emotion regulation brain activity in patients and comparison across the OCD-related regulation contrast allows us to speculate about the function of diseasespecific emotion regulation systems in OCD.

Further, like other reports of trend-level or task-order dependent effects of rTMS (Guse et al. 2010; van den Heuvel et al. 2013), our behavioral results from the rTMS challenge were present at liberal trend-level only. Although additional evidence, relating the changes in distress to changes in brain activity in relevant emotion processing and regulation brain areas, point to a similar conclusion, our rTMS results should be interpreted with caution and await empirical replication. Although comorbidity did not influence emotion regulation capabilities at baseline, a possible interaction of co-morbid diagnosis and response to rTMS cannot be excluded, given the significantly higher incidence of co-morbid diagnoses in patients randomly assigned to real $v$. sham rTMS.

The present study also has important strengths. First, we assessed emotion processing and regulation in a relatively large medication-free OCD sample. Second, we accounted for differential timing of neural processes during emotion provocation in our analysis. Third, we aimed to optimize modulatory effects of rTMS by using a functionally-localized hotspot under neuronavigation (Sack et al. 2009).

\section{Conclusion}

To conclude, we observed frontal-limbic and frontalparietal dysfunction during effortful emotion regulation in OCD. Modulation of cortical excitability using rTMS over left dIPFC appears to affect automatic emotion regulatory processes, possibly by changing frontal-limbic connectivity.

\section{Supplementary material}

For supplementary material accompanying this paper visit http://dx.doi.org/10.1017/S0033291715001026.

\section{Acknowledgements}

This study was funded by The Netherlands Organisation for Scientific Research (NWO-ZonMw VENI grant 916.86.036, Dr O. A. van den Heuvel), Brain \& Behavior Research Foundation (NARSAD Young Investigators Award 2009, Dr O. A. van den Heuvel), the Netherlands Brain Foundation (2010 (1)-50), and the Amsterdam Brain Imaging Platform. The authors thank Yvette van der Pas (psychologist/ psychotherapist) for her help devising the reappraisal instruction protocol. Also, we thank Danielle Cath (psychiatrist) for her help during patient inclusion, and Lisanne van der Bijl (MD), Vionne van der Borden (MSc), Eveline M. Veltman (MSc), Sander J. C. Verfaillie (MSc), Chris Vriend (PhD) and Froukje

E. de Vries (MD) for their help during data collection.

\section{Declaration of Interest}

None.

\section{References}

APA (2013). Diagnostic and Statistical Manual of Mental Disorders, 5th edn (DSM-5). American Psychiatric Publishing: Arlington, VA.

Caseras X, Mataix-Cols D, Trasovares MV, Lopez-Sola M, Ortriz H, Pujol J, Soriano-Mas C, Giampietro V, Brammer MJ, Torrubia R (2010). Dynamics of brain responses to phobic-related stimulation in specific phobia subtypes. European Journal of Neuroscience 32, 1414-1422.

Conca A, Di Pauli J, Beraus W, Hausmann A, Peschina W, Schneider H, Konig P, Hinterhuber H (2002). Combining high and low frequencies in rTMS antidepressive treatment: preliminary results. Human Psychopharmacology 17, 353-356.

de Vries FE, de Wit SJ, Cath DC, van der Werf YD, van der Borden V, van Rossum TB, van Balkom AJ, van der Wee NJ, Veltman DJ, van den Heuvel OA (2014).

Compensatory frontoparietal activity during working memory: an endophenotype of obsessive-compulsive disorder. Biological Psychiatry 76, 878-887.

de Wit SJ, Alonso P, Schweren L, Mataix-Cols D, Lochner C, Menchon JM, Stein DJ, Fouche JP, Soriano-Mas C, Sato JR, Hoexter MQ, Denys D, Nakamae T, Nishida S, Kwon JS, Jang JH, Busatto GF, Cardoner N, Cath DC, Fukui K, Jung WH, Kim SN, Miguel EC, Narumoto J, Phillips ML, Pujol J, Remijnse PL, Sakai Y, Shin NY, Yamada K, Veltman DJ, van den Heuvel OA (2014). Multicenter voxel-based morphometry mega-analysis of structural brain scans in obsessive-compulsive disorder. American Journal of Psychiatry 171, 340-349.

de Wit SJ, de Vries FE, van der Werf YD, Cath DC, Heslenfeld DJ, Veltman EM, van Balkom AJ, Veltman DJ, van den Heuvel OA (2012). Presupplementary motor area hyperactivity during response inhibition: a candidate endophenotype of obsessive-compulsive disorder. American Journal of Psychiatry 169, 1100-1108. 
Dosenbach NU, Fair DA, Miezin FM, Cohen AL, Wenger KK, Dosenbach RA, Fox MD, Snyder AZ, Vincent JL, Raichle ME, Schlaggar BL, Petersen SE (2007). Distinct brain networks for adaptive and stable task control in humans. Proceedings of the National Academy of Sciences USA 104, 11073-11078.

Drabant EM, McRae K, Manuck SB, Hariri AR, Gross JJ (2009). Individual differences in typical reappraisal use predict amygdala and prefrontal responses. Biological Psychiatry 65, 367-373.

Erk S, Mikschl A, Stier S, Ciaramidaro A, Gapp V, Weber B, Walter $\mathbf{H}$ (2010). Acute and sustained effects of cognitive emotion regulation in major depression. Journal of Neuroscience 30, 15726-15734.

First MB, Spitzer RL, Gibbon M, Williams JBW (2002). Structured Clinical Interview for DSM-IV-TR Axis I Disorders, Research Version, Patient Edition (SCID I/P). Biometrics Research, New York State Psychiatric Institute: New York, NY.

Franklin ME, Foa EB (2011). Treatment of obsessive compulsive disorder. Annual Review of Clinical Psychology 7, 229-243.

Ghashghaei HT, Hilgetag CC, Barbas H (2007). Sequence of information processing for emotions based on the anatomic dialogue between prefrontal cortex and amygdala. Neuroimage 34, 905-923.

Goldin PR, Manber-Ball T, Werner K, Heimberg R, Gross JJ (2009a). Neural mechanisms of cognitive reappraisal of negative self-beliefs in social anxiety disorder. Biological Psychiatry 66, 1091-1099.

Goldin PR, Manber T, Hakimi S, Canli T, Gross JJ (2009b). Neural bases of social anxiety disorder: emotional reactivity and cognitive regulation during social and physical threat. Archives of General Psychiatry 66, 170-180.

Goldin PR, McRae K, Ramel W, Gross JJ (2008). The neural bases of emotion regulation: reappraisal and suppression of negative emotion. Biological Psychiatry 63, 577-586.

Goldin PR, Ziv M, Jazaieri H, Hahn K, Heimberg R, Gross JJ (2013). Impact of cognitive behavioral therapy for social anxiety disorder on the neural dynamics of cognitive reappraisal of negative self-beliefs: randomized clinical trial. JAMA Psychiatry 70, 1048-1056.

Goodman WK, Price LH, Rasmussen SA, Mazure C, Fleischmann RL, Hill CL, Heninger GR, Charney DS (1989). The yale-brown obsessive compulsive scale. I. Development, use, and reliability. Archives of General Psychiatry 46, 1006-1011.

Gross JJ, John OP (2003). Individual differences in two emotion regulation processes: implications for affect, relationships, and well-being. Journal of Personality and Social Psychology 85, 348-362.

Guse B, Falkai P, Wobrock T (2010). Cognitive effects of high-frequency repetitive transcranial magnetic stimulation: a systematic review. Journal of Neural Transmission 117, 105-122.

Gyurak A, Gross JJ, Etkin A (2011). Explicit and implicit emotion regulation: a dual-process framework. Cognition and Emotion 25, 400-412.

Harmer CJ, Thilo KV, Rothwell JC, Goodwin GM (2001). Transcranial magnetic stimulation of medial-frontal cortex impairs the processing of angry facial expressions. Nature Neuroscience 4, 17-18.

Hermann A, Schafer A, Walter B, Stark R, Vaitl D, Schienle A (2009). Emotion regulation in spider phobia: role of the medial prefrontal cortex. Social Cognitive and Affective Neuroscience 4, 257-267.

Huyser C, Veltman DJ, Wolters LH, de Haan E, Boer F (2010). Functional magnetic resonance imaging during planning before and after cognitive-behavioral therapy in pediatric obsessive-compulsive disorder. Journal of the American Academy of Child and Adolescent Psychiatry 49, 1238-1248.

Johnstone T, van Reekum CM, Urry HL, Kalin NH, Davidson RJ (2007). Failure to regulate: counterproductive recruitment of top-down prefrontal-subcortical circuitry in major depression. Journal of Neuroscience 27, 8877-8884.

Kalisch R (2009). The functional neuroanatomy of reappraisal: time matters. Neuroscience and Biobehavioral Reviews 33, 1215-1226.

Kanske P, Heissler J, Schonfelder S, Wessa M (2012). Neural correlates of emotion regulation deficits in remitted depression: the influence of regulation strategy, habitual regulation use, and emotional valence. Neuroimage 61, 686-693.

Koole SL, Jostmann NB (2004). Getting a grip on your feelings: effects of action orientation and external demands on intuitive affect regulation. Journal of Personality and Social Psychology 87, 974-990.

Lang S, Kotchoubey B, Frick C, Spitzer C, Grabe HJ, Barnow S (2012). Cognitive reappraisal in trauma-exposed women with borderline personality disorder. Neuroimage 59, 1727-1734.

Larson CL, Schaefer HS, Siegle GJ, Jackson CA, Anderle MJ, Davidson RJ (2006). Fear is fast in phobic individuals: amygdala activation in response to fear-relevant stimuli. Biological Psychiatry 60, 410-417.

Lieberman MD, Cunningham WA (2009). Type I and Type II error concerns in fMRI research: re-balancing the scale. Social Cognitive and Affective Neuroscience 4, 423-428.

Maldjian JA, Laurienti PJ, Kraft RA, Burdette JH (2003). An automated method for neuroanatomic and cytoarchitectonic atlas-based interrogation of fMRI data sets. Neuroimage 19, 1233-1239.

Mataix-Cols D, van den Heuvel OA (2006). Common and distinct neural correlates of obsessive-compulsive and related disorders. Psychiatric Clinics of North America 29, 391-410, viii.

McLaren DG, Ries ML, Xu G, Johnson SC (2012). A generalized form of context-dependent psychophysiological interactions (gPPI): a comparison to standard approaches. Neuroimage 61, 1277-1286.

Menzies L, Chamberlain SR, Laird AR, Thelen SM, Sahakian BJ, Bullmore ET (2008). Integrating evidence from neuroimaging and neuropsychological studies of obsessive-compulsive disorder: the orbitofronto-striatal model revisited. Neuroscience and Biobehavioral Reviews 32, 525-549.

Milad MR, Furtak SC, Greenberg JL, Keshaviah A, Im JJ, Falkenstein M, Jenike M, Rauch SL, Wilhelm S (2013). 
Deficits in conditioned fear extinction in obsessivecompulsive disorder correlated to neurobiological changes in the fear circuit. JAMA Psychiatry 70, 608-618.

Montgomery SA, Åsberg M (1979). A new depression scale designed to be sensitive to change. British Journal of Psychiatry 134, 382-389.

Moritz S, Von Muhlenen A, Randjbar S, Fricke S, Jelinek L (2009). Evidence for an attentional bias for washing- and checking-relevant stimuli in obsessive-compulsive disorder. Journal of the International Neuropsychological Society 15, 365-371.

New AS, Fan J, Murrough JW, Liu X, Liebman RE, Guise KG, Tang CY, Charney DS (2009). A functional magnetic resonance imaging study of deliberate emotion regulation in resilience and posttraumatic stress disorder. Biological Psychiatry 66, 656-664.

Ochsner KN, Gross JJ (2007). The neural architecture of emotion regulation. In Handbook of Emotion Regulation (ed. J. J. Gross), pp. 87-105. Guildford Press: New York, NY.

Ochsner KN, Ray RD, Cooper JC, Robertson ER, Chopra S, Gabrieli JD, Gross JJ (2004). For better or for worse: neural systems supporting the cognitive down- and up-regulation of negative emotion. Neuroimage 23, 483-499.

Ochsner KN, Silvers JA, Buhle JT (2012). Functional imaging studies of emotion regulation: a synthetic review and evolving model of the cognitive control of emotion. Annals of the New York Academy of Sciences 1251, E1-E24.

Oldfield RC (1971). The assessment and analysis of handedness: the Edinburgh inventory. Neuropsychologia 9, 97-113.

Pezawas L, Meyer-Lindenberg A, Drabant EM, Verchinski BA, Munoz KE, Kolachana BS, Egan MF, Mattay VS, Hariri AR, Weinberger DR (2005). 5-HTTLPR polymorphism impacts human cingulate-amygdala interactions: a genetic susceptibility mechanism for depression. Nature Neuroscience 8, 828-834.

Phillips ML, Drevets WC, Rauch SL, Lane R (2003a). Neurobiology of emotion perception I: the neural basis of normal emotion perception. Biological Psychiatry 54, 504-514.

Phillips ML, Drevets WC, Rauch SL, Lane R (2003b). Neurobiology of emotion perception II: implications for major psychiatric disorders. Biological Psychiatry 54, 515-528.

Reithler J, Peters JC, Sack AT (2011). Multimodal transcranial magnetic stimulation: using concurrent neuroimaging to reveal the neural network dynamics of noninvasive brain stimulation. Progress in Neurobiology 94, 149-165.

Remijnse PL, Nielen MM, van Balkom AJ, Cath DC, van Oppen P, Uylings HB, Veltman DJ (2006). Reduced orbitofrontal-striatal activity on a reversal learning task in obsessive-compulsive disorder. Archives of General Psychiatry 63, 1225-1236.

Rossi S, Hallett M, Rossini PM, Pascual-Leone A, Safety of, T. M S. C. G. (2009). Safety, ethical considerations, and application guidelines for the use of transcranial magnetic stimulation in clinical practice and research. Clinical Neurophysiology 120, 2008-2039.
Rotge JY, Guehl D, Dilharreguy B, Cuny E, Tignol J, Bioulac B, Allard M, Burbaud P, Aouizerate B (2008). Provocation of obsessive-compulsive symptoms: a quantitative voxel-based meta-analysis of functional neuroimaging studies. Journal of Psychiatry \& Neuroscience 33, 405-412.

Sack AT, Cohen Kadosh R, Schuhmann T, Moerel M, Walsh V, Goebel R (2009). Optimizing functional accuracy of TMS in cognitive studies: a comparison of methods. Journal of Cognitive Neuroscience 21, 207-221.

Schienle A, Schafer A, Stark R, Walter B, Vaitl D (2005). Neural responses of OCD patients towards disorder-relevant, generally disgust-inducing and fear-inducing pictures. International Journal of Psychophysiology 57, 69-77.

Schuurmans J, van Balkom AJ, van Megen HJ, Smit JH, Eikelenboom M, Cath DC, Kaarsemaker M, Oosterbaan D, Hendriks GJ, Schruers KR, van der Wee NJ, Glas G, van Oppen P (2012). The Netherlands Obsessive Compulsive Disorder Association (NOCDA) study: design and rationale of a longitudinal naturalistic study of the course of OCD and clinical characteristics of the sample at baseline. International Journal of Methods in Psychiatric Research 21, 273-285.

Siebner HR, Bergmann TO, Bestmann S, Massimini M, Johansen-Berg $H$, Mochizuki $H$, Bohning DE, Boorman ED, Groppa S, Miniussi C, Pascual-Leone A, Huber R, Taylor PC, Ilmoniemi RJ, De Gennaro L, Strafella AP, Kahkonen S, Kloppel S, Frisoni GB, George MS, Hallett M, Brandt SA, Rushworth MF, Ziemann U, Rothwell JC, Ward N, Cohen LG, Baudewig J, Paus T, Ugawa Y, Rossini PM (2009). Consensus paper: combining transcranial stimulation with neuroimaging. Brain Stimulation 2, 58-80.

van den Heuvel OA, Van Gorsel HC, Veltman DJ, Van Der Werf YD (2013). Impairment of executive performance after transcranial magnetic modulation of the left dorsal frontal-striatal circuit. Human Brain Mapping 34, 347-355.

van den Heuvel OA, Veltman DJ, Groenewegen HJ, Cath DC, van Balkom AJ, van Hartskamp J, Barkhof F, van Dyck R (2005a). Frontal-striatal dysfunction during planning in obsessive-compulsive disorder. Archives of General Psychiatry 62, 301-309.

van den Heuvel OA, Veltman DJ, Groenewegen HJ, Dolan RJ, Cath DC, Boellaard R, Mesina CT, van Balkom AJ, van Oppen P, Witter MP, Lammertsma AA, van Dyck $R$ (2004). Amygdala activity in obsessive-compulsive disorder with contamination fear: a study with oxygen-15 water positron emission tomography. Psychiatry Research 132, 225-237.

van den Heuvel OA, Veltman DJ, Groenewegen HJ, Witter MP, Merkelbach J, Cath DC, van Balkom AJ, van Oppen P, van Dyck R (2005b). Disorder-specific neuroanatomical correlates of attentional bias in obsessive-compulsive disorder, panic disorder, and hypochondriasis. Archives of General Psychiatry 62, 922-933. van der Werf YD, Sanz-Arigita EJ, Menning S, van den Heuvel OA (2010). Modulating spontaneous brain activity 
using repetitive transcranial magnetic stimulation. $B M C$ Neuroscience 11, 145.

Van Oppen P, Hoekstra RJ, Emmelkamp PM (1995). The structure of obsessive-compulsive symptoms. Behaviour Research and Therapy 33, 15-23.

Volman I, Roelofs K, Koch S, Verhagen L, Toni I (2011). Anterior prefrontal cortex inhibition impairs control over social emotional actions. Current Biology 21, 1766-1770.

Vriend C, de Wit SJ, Remijnse PL, van Balkom AJ, Veltman DJ, van den Heuvel OA (2013). Switch the itch: a naturalistic follow-up study on the neural correlates of cognitive flexibility in obsessive-compulsive disorder. Psychiatry Research 213, 31-38.

Waugh CE, Hamilton JP, Gotlib IH (2010). The neural temporal dynamics of the intensity of emotional experience. Neuroimage 49, 1699-1707.

Worsley KJ, Marrett S, Neelin P, Vandal AC, Friston KJ, Evans AC (1996). A unified statistical approach for determining significant signals in images of cerebral activation. Human Brain Mapping 4, 58-73. 